\title{
Niepokoje końca wieku. Sanitarium i rekonwalescencja amerykańskiej tożsamości
}

Turn-of-the-century anxieties. Sanitarium and the recovery of American identity

\section{Wojciech Sitek}

Uniwersytet Śląski w Katowicach

wojciech.sitek@us.edu.pl | ORCID: 0000-0002-4550-7679

\begin{abstract}
American popular culture in the nineties gave birth to the trend of pessimistic stories set in nightmare aesthetics. Authors of the games like Sanitarium recalled the memory of historical losses and also warned about future disasters. In this article the game made by the DreamForge Intertainment studio is analyzed as a representation of the damaged American identity. On the one hand, Sanitarium is about the social crisis that hit the USA at the end of the millennium. On the other hand, the meaning of the whole game is filled with trust in the recovery of America's moral strength.
\end{abstract}

Keywords: American culture, new millennium fears, video games, Sanitarium 

W Stasis (2015) kilkuletnia dziewczynka dzieli się obawami z ojcem: „Jeśli masz zły sen i nie możesz się obudzić, to zostaniesz w tym śnie na zawsze". Córka Johna Marachecka będzie później zasypiać i budzić się zgodnie z wolą liderów korporacji Cayne, a w końcu bezsensownie zginie, powtarzając los wielu ofiar późnego kapitalizmu. W świecie przypominającym skompromitowane laboratorium stale powracają przestrogi nakreślone w grze Sanitarium (1998). O ile w Stasis nowy imperializm zyskuje kształt okrzepłej i nienaruszalnej już antyutopii, o tyle w grze powstałej u schyłku XX wieku proroczo wybrzmiewają ostrzeżenia przed ekspansją doktryny neoliberalnej.

Fabuła Sanitarium koncentruje się na wewnętrznej podróży bohatera, który ugrzązł w wielopoziomowym koszmarze. Próba zespolenia rozbitej tożsamości jednostki odsłania jednak znacznie szerszy kontekst. Ostatecznie rekonstrukcja życiorysu Maksa daje wgląd w bolączki amerykańskiego społeczeństwa u schyłku tysiąclecia. W przeciwieństwie do nieoficjalnej, południowoafrykańskiej kontynuacji z 2015 roku Sanitarium odznacza się krzepiącym charakterem, wskazując na szansę odzyskania równowagi. Po ponad dwudziestu latach od premiery optymistyczny na pozór epilog może jednak budzić wątpliwości. Jeśli przyjąć, że analogie między bohaterami obu gier są nieprzypadkowe i Maracheck jest przyszłą inkarnacją Maksa z Sanitarium, to szczęśliwe zakończenie pierwowzoru stanowiłoby zaledwie preludium faktycznej apokalipsy. Być może byłoby lepiej, gdyby Max nigdy nie wydostał się z zakładu psychiatrycznego'. Wszak to na gruncie afirmowanej przez niego ideologii wyrośnie zbrodnicza korporacja Cayne.

\section{W przededniu apokalipsy}

Grę Sanitarium otwiera sekwencja wideo, której centralnym punktem jest moment wypadku samochodowego głównego bohatera. Dalsze losy

${ }^{1}$ Istnieje jeszcze inna możliwość: wydarzenia przedstawione w Stasis są kolejnym poziomem fantazji Maksa z Sanitarium, w której pojawiają się jego żona i dziecko. Zważywszy na powtarzalność pewnych motywów (eksperymenty biotechnologiczne, rozrost roślinności, obecność niebezpiecznych owadów, przebudzenie po długim śnie, korporacyjne nadużycia), propozycja ta jest jedną z opcji interpretacyjnych. 
mężczyzny wymykają się jednoznacznym rozstrzygnięciom. Wydaje się, że po zdarzeniu Max trafia do szpitala psychiatrycznego - najwyraźniej obrażenia fizyczne zagrażają mu w mniejszym stopniu niż szok utrwalający powypadkową amnezję. Kolejne przesłanki sygnalizują, że wprowadzenie do rozgrywki jest zobiektywizowane jedynie pozornie, a zrelacjonowane w nim wydarzenia przynależą do sfery fantazmatycznych projekcji pierwszoplanowej postaci. Z pewną dozą ostrożności można jednak dokonać dwóch wstępnych założeń. Po pierwsze bohater pozostaje w stanie śpiączki, a wszystkie zdarzenia mające miejsce po kraksie rozgrywają sięjuż wyłącznie w jego psychice. Po drugie Max doświadcza kryzysu tożsamościowego, który nie ma większego związku z wypadkiem samochodowym. Powrót do równowagi wewnętrznej jest zatem powiązany z procesem wydostawania się z wyobrażonej przestrzeni szpitala. W fantasmagorycznym świecie Max początkowo przesadnie zawierza swoim zdolnościom poznawczym i ignoruje przesłanki dla zakwestionowania obiektywizmu własnego spojrzenia. Dopóki bohater nie uświadomi sobie postępującej erozji psychicznej, dopóty pozostanie więźniem limbo, niczym nieszczęśnicy z filmów Drabina Jakubowa (1990) i 12 małp (1995), które wyraźnie inspirowały twórców Sanitarium (Pasetto, 1998).

Wgląd w zaburzoną psychikę głównego bohatera gry daje zwłaszcza wizjonerskie dzieło Terry'ego Gilliama. W 12 małpach jeden z pacjentów „domu wariatów” odżegnuje się od związków z obcymi z planety Ogo. Zmysły podpowiadają mu przynależność do kosmicznej elity intelektualnej, której celem jest ujarzmienie „barbarzyńskich” hord z Plutona (lub Iraku w przyziemnej interpretacji ${ }^{2}$ ), jednak mężczyzna zdroworozsądkowo deklaruje: „Chociaż ta rzeczywistość jest dla mnie całkowicie przekonująca, tak naprawdę to jedynie wytwór mojej psyche. Mój umysł uległ rozszczepieniu. W ten sposób uciekam przed pewnymi nienazwanymi okoliczności, które zatruwają moją tutejszą egzystencję"3. Świadomość szaleństwa jest w dziele Gilliama oznaką nadzwyczajnej mądrości. Przysłuchujący się tyradzie protagonista ignoruje wypowiedź rekonwalescenta, bo nie dostrzega kluczowej analogii między swoją

\footnotetext{
${ }^{2}$ Jak zauważa Geoffrey Wiseman, zdaniem niektórych komentatorów wojna w Zatoce Perskiej była interwencją uprawnioną i zasadną, bo dotyczącą „barbarzyńskiego” rejonu świata (Wiseman, 2001, s. 147-148, 264).

${ }^{3}$ Cytat pochodzi z polskiej wersji językowej filmu 12 matp.
} 
postawą a rojeniami „kosmicznego intelektualisty”. Sam bezrefleksyjnie uznaje się przecież za przybysza z przyszłości, który nie tylko poszukuje w 1996 roku ratunku dla swoich towarzyszy zagrożonych oddziaływaniem niebezpiecznego patogenu, ale też przestrzega - jak mniema - przodków przed konsekwencjami nadchodzącego kataklizmu.

Alarmistyczne diagnozy w 12 małpach sytuują się daleko od naiwnego wieszczbiarstwa. W kluczowej dla interpretacji filmu scenie jedna z bohaterek - wykładowczyni akademicka - sygnalizuje nonsens wszelkich antycypacji przyszłości. W jej przekonaniu snucie wizji dnia jutrzejszego jest zwykle podyktowane jednostkowymi traumami. Z czasem propozycja antropolożki będzie coraz silniej uzewnętrzniać się w działaniach Jamesa Cole’a, przeświadczonego o nadciągającej apokaliptycznej epidemii. Profetyczna intuicja głównego bohatera w niewielkim stopniu przekłada się na zmianę społeczną. W spetryfikowanym świecie zagłada wydaje się nieuchronna.

Gilliam akcentuje w 12 małpach rozziew między subiektywnym widzeniem świata i faktycznym kształtem rzeczywistości. Max z Sanitarium, pozostając pod wpływem amerykańskiego kultu indywidualizmu, także bagatelizuje piętno społecznej zapaści. W otwierającej grę sekwencji bohater dzwoni do żony, by przekazać jej wiadomość: „Znalazłem odpowiedź! Przez tyle lat... Powinienem był się domyślić. Jest tego więcej! Opowiem ci wszystko w domu". Choć tajemniczy komunikat stanie się później elementem historii o opracowaniu lekarstwa na śmiertelną chorobę, to zaskakujący, konspiracyjny szept bohatera sugeruje inne odkrycie: rozpoznanie realiów późnego kapitalizmu. Nagrany komunikat może wskazywać, że bohater wyzbywa się naiwnych fantazji o ratowaniu ludzkości w duchu wspólnotowym. Praca w korporacji zdążyła nauczyć go innej prawdy: bezdusznej logiki biznesowej. Tuż po wygłoszeniu zaszyfrowanej wiadomości w strukturze umysłu Maksa pojawia się pęknięcie - zobrazowane też dosłownie roztrzaskaniem barier ochronnych i rozbiciem samochodu. Zgruchotaną mentalność schizofrenika będzie mogła ukoić jedynie akceptacja „tu i teraz”.

W Stanach Zjednoczonych schyłku XX wieku złowieszcze przepowiednie towarzyszyły wielu sferom życia codziennego. Entuzjazm wyróżniający epokę Ronalda Reagana dogasał, a niespełnione fantazje o nadejściu „poranka w Ameryce” kładły się cieniem na rządach republikanów. 
Orientacja przyszłościowa ustąpiła miejsca wyobrażeniom „lepszego wczoraj". Rozsadzenie optymizmu narodu amerykańskiego zbiegło się w czasie z głoszeniem alarmistycznych diagnoz i dokonywaniem ponurych milenijnych podsumowań (por. Troy, 2013, s. 16-17). Wbrew pozorom zmiana warty roku 1993 nie odmieniła nastrojów wyzwolonych przez przyjęty w latach 8o. kurs ideologiczny. Praktyki polityczno-ekonomiczne późnego kapitalizmu utrwaliły się, a przymierze między wielkim biznesem i konserwatystami zostało zachowane.

Choć w refleksji ludologicznej Sanitarium było zwykle przywoływane pretekstowo, jako tytuł istotny dla tradycji horroru psychodelicznego (Kilgore, 2007, s.7; Marak, 2021, s.58), to podjęta przez twórców problematyka wyraźnie lokuje grę w pejzażu przeobrażeń końca wieku (por. Valentine, Jensen, 2016, s. 64). Sanitarium odzwierciedla obawy cechujące amerykańską codzienność lat 90., wywodząc je z poczynań przedstawicieli paradoksalnego sojuszu liberalnych elit i konserwatystów. Wspomniany alians zyskuje w fabule dwóch reprezentantów - na pozór wrogo do siebie nastawionych, lecz w istocie współpracujących w ramach nurtu neokonserwatywnego. Zdegenerowany Jacob Morgan jako rzecznik korporacji medycznej dokonuje pochwały ideologii wolnorynkowej, a dobrotliwy główny bohater podejmuje indywidualne inicjatywy, w których manifestuje się wiara w możliwość spełnienia amerykańskiego snu.

\section{Profetyczny obłęd}

U schyłku poprzedniego tysiąclecia dokonało się chwilowe przemieszanie kategorii: opadła konserwatywna maska neoliberalizmu i w konsekwencji odsłonił się paranoiczny model uprawiania polityki w Stanach Zjednoczonych. Reagan, prezydent mocarstwa, który swoje decyzje konsultował z wróżką (Wheen, 2012, s.117-157), intuicyjnie sięgał do retoryki czasów ostatecznych i napędzał społeczny lęk przed demonicznymi siłami, podobnie jak robili to milenaryści, przewidujący koniec świata (Hofstadter, 1996, s.30). Jednocześnie lider imperium wzmacniał idę̨ amerykańskiej wyjątkowości, przypominając o przymierzu narodu amerykańskiego z Bogiem (Hodgson, 2009, s.110-111). Kiedy w czasie prezydentury Billa Clintona na moment odsłoniła się iluzja Reaganowskiej 
moralnej wyższości, rezygnacja z biblijnej ornamentyki w dyskursie publicznym zachwiała wiarą w hegemonię Stanów Zjednoczonych. Protagonista Sanitarium odzyskuje narodowe cnoty - to na jego barkach spoczywa odpowiedzialność za los odwiedzanych krain. Choć poszczególne czasoprzestrzenie są nawiedzane przez kolejne nieszczęścia, a towarzyszące im złe omeny wynikają z upadku amerykańskiego ducha, Max podejmuje działania na rzecz przywrócenia mitycznej wyjątkowości.

$\mathrm{Na}$ fantazje kształtowane w latach 80. przez administrację Reagana nałożyły się antycypacje niebezpieczeństw kolejnego tysiąclecia. Pod koniec milenium wyobraźnia podsuwała Amerykanom przekonujące obrazy przyszłości, naznaczone tematami wojny i uchodźstwa, ataków terrorystycznych, rywalizacji o zasoby, plag i epidemii, skażeń środowiska, awarii technologicznych, klęsk żywiołowych i głodu. Podobnie dzieje się w Sanitarium, gdzie kometa zapowiada tragedię w niewielkiej osadzie, a krwawy płacz posągu anioła obwieszcza nieuchronną śmierć dzieci. Apokaliptyczne przepowiednie uzmysławiały eskalację „kultury strachu” napędzanej przekonaniem, że w czasach przełomów ludzkość musi mierzyć się z potężnymi siłami zagrażającymi jej egzystencji (Furedi, 2006, s.X). Kiedy rozpadał się fasadowy optymizm, wybrzmiała nieufność wobec wszelkich formacji wspólnotowych. Obsesyjna fantazja Maksa o odkryciu lekarstwa jest wyraźną manifestacją procesu opisanego przez Barry'ego Glassnera w Kulturze strachu. U schyłku XX wieku socjolog dostrzegł odwrót od systemowych rozwiązań na rzecz promocji indywidualizmu, skutkujący przeniesieniem odpowiedzialności za własny dobrostan na jednostkę (Glassner, 2000, 5. 78). W latach 90. marzenie o utopijnej przyszłości dla wszystkich rozwiało się pod naporem apokaliptycznych wizji, które ukazywano w tekstach kultury popularnej (Lamy, 1996, s. VI). Część przekazów, między innymi Sanitarium, proponowała pozornie optymistyczny wariant wyjścia z kryzysu. Maksowi, jako modelowemu indywidualiście, końcowe powodzenie zapewnia działanie zgodne z regułami wolnorynkowego kapitalizmu.

\section{Pęknięte tożsamości}

$\mathrm{Na}$ przełomie tysiącleci wątpliwości egzystencjalne legły u podstaw zbiorowej trwogi nie tylko w gronie przedstawicieli ruchów religijnych, 
surwiwalowych paranoików i zwolenników teorii spiskowych, ale też dziennikarzy i polityków. Diagnozy stawiane przez intelektualistów pokroju Samuela Huntingtona i Francisa Fukuyamy, niezależnie od wydźwięku ideologicznego, sygnalizowały kres czegoś i legitymizowały kasandryczne przepowiednie (Wheen, 2012, s. 64-77). Trudności w zdefiniowaniu nadciągających zagrożeń w „realnej rzeczywistości” szły w parze z zainteresowaniami twórców kultury popularnej, którzy powoływali do istnienia fantazmaty. Amerykańscy autorzy reagowali na przewidywaną katastrofę, przed którą wysiłki wspólnotowe zdawały się nie chronić. Relacje z procesu tworzenia Sanitarium potwierdzają obecność defetystycznych nastrojów w Stanach Zjednoczonych. Chris Pasetto, jeden z producentów gry, zwracał uwagę, że przed przystąpieniem do prac członkowie zespołu DreamForge Intertainment byli pogrążeni w apatii. Na etapie koncepcyjnym projektanci poświęcali więcej uwagi wizualizacjom dotykających ich niepokojów niż tradycyjnym burzom mózgów. Ostatecznie prywatne wyobrażenia poszczególnych uczestników projektu wkomponowano w obszerniejszą mozaikę amerykańskich lęków (Pasetto, 1998).

$\mathrm{Na}$ progu nowego tysiąclecia kultura popularna często wychodziła naprzeciw egzystencjalnym obawom. We wprowadzeniu do monografii poświęconej narracjom puzzlowym ${ }^{4}$ Warren Buckland zauważył, że kreowane w latach 9o. światy przedstawione sprawiały wrażenie złożonych i nieprzejrzystych. Zdaniem badacza sfera codziennego doświadczenia przybrała formę fragmentaryczną, więc tradycyjne sposoby konstruowania tożsamości i opowiadania historii musiały się wyczerpać (Buckland, 2009, s. 1). W filmach, serialach (przykładowo Z Archiwum X, 1993-2002, Amerykański horror, 1995-1996 i Millennium, 1996-1999) i grach wideo rolę centralnych punktów narracji zaczęły odgrywać tajemnica i niepewność. Forpocztą nurtu interaktywnej rozrywki eksplorującego stany paranoiczne i schizofreniczne zostały między innymi Dark Seed (1992) i Dark Seed II (1995), I Have No Mouth, and I Must Scream (1995), Chronomaster (1995) oraz Harvester (1996), które nie

4 Puzzle films, określane też mianem mind-game films, prowadzą eksperymenty z klasyczną narracją, są ukierunkowane na wywołanie u widza dezorientacji i dyskomfortu, a ich wyznacznikami są między innymi: zerwanie z liniowością opowiadania, operowanie pętlami czasowymi, kwestionowanie ciągłości czasowo-przestrzennej, zacieranie granic między różnymi poziomami rzeczywistości, nagromadzenie zagadek czy niewiarygodna instancja narratora (Buckland, 2009, s. 6). 
tylko sięgały do motywów historii, pamięci i teraźniejszych zgryzot, ale też antycypowały nadciągający kres. Sanitarium wpisało się w ten sam trend.

\section{W czasie poza czasem}

Panoptyczna przestrzeń szpitala psychiatrycznego, w której rozpoczyna się akcja gry, przywodzi na myśl budynek wiedeńskiego Narrenturm. Zdaniem Alfreda Stohla w pozaczasowej Wieży Błaznów romantyczne myślenie magiczne i oświeceniowe uznanie dla rozumu ciągle wchodziło ze sobą w dialog (Stohl, 2000, s. 7-13, za: Kornberger, 2014, s. 105). W wieży szaleństwa z Sanitarium - pierwszym poziomie fantazji Maksa rozpoczyna się z kolei metaforyczna podróż przez kolejne czasoprzestrzenie portretujące lęki bohatera, w której finale dokonuje się pochwała etyki troski i wolnorynkowego indywidualizmu. Poszczególne przygody, ufundowane na wielu symbolach amerykańskiej mitologii, są związane z różnymi wersjami przeszłości, alternatywnymi teraźniejszościami i wariantami możliwych przyszłości. Wszystkie one - mimo towarzyszącego graczowi złudzenia stopniowego odkrywania historii - od samego początku wypływają ze świadomości bohatera. Taką interpretację sugeruje obecność w szpitalu wielobarwnych witraży, w których ujęte są komentarze na temat przyszłych poczynań Maksa. Świat Sanitarium może początkowo jawić się jako składowisko niepowiązanych ze sobą tropów społecznych i kulturowych. W trakcie rozgrywki między poszczególnymi wątkami tworzy się wyraźna siatka powiązań, dająca wgląd w kształt amerykańskiej tożsamości na przełomie wieków.

Jak zauważył Markus Rautzenberg na przykładzie gier Silent Hill (1999) i Planescape: Torment (1999), strach przed niepewnością może prowadzić do krain szaleństwa (Rautzenberg, 2015, s. 89). Szpital psychiatryczny, miejsce nadrzędne wobec innych fantazji Maksa (podobny schemat proponowały filmy Wyspa tajemnic, 2010, i Sucker Punch, 2011, przyjmujące za wzorzec Gabinet doktora Caligari, 1920), jest wytworem koszmaru, z którego bohater ma szansę jeszcze się wybudzić. Rozpoczynające się w lecznicy wędrówki krok po kroku odsłaniają życiorys Maksa. W końcu dowiadujemy się, że bohater jest badaczem rozpoznającym śmiertelną chorobę, która dziesiątkuje młodych pacjentów. 
Opowieść o zagłębianiu się w psychikę bohatera, zrekonstruowana w sposób diachroniczny, miałaby swój początek w obnażeniu patologii późnego kapitalizmu. W Sanitarium wyrzut czyniony systemowi dotyczy w pierwszym rzędzie powszechnej prywatyzacji i cięć kosztów publicznych. W kraju, w którym propozycje upaństwowienia służby zdrowia są traktowane niczym wyraz socjalistycznych sympatii, nobilituje się mniej efektywne placówki prywatne i sprzyja interesom firm farmaceutycznych (Steger, 2009, s. 55). Praca w korporacji Jacoba Morgana wymaga od Maksa ciągłego zabiegania o środki na prowadzenie badań. Firma Nadzieja nie ma bowiem na celu wspierania prac rozwojowych, lecz monetyzowanie dotychczas opatentowanych rozwiązań. Mimo to bohater wciąż zawierza amerykańskiej ideologii sukcesu. Zgodnie z jej dogmatami podejmuje jednostkową aktywność. Prowadzi nieoficjalne, lecz skuteczne starania, by zgodnie z duchem czasów samodzielnie odnaleźć lekarstwo na śmiertelną chorobę na gruncie popularnych w latach 80. i 90. terapii alternatywnych.

Historia nadkruszonej tożsamości rodzi się na gruncie konserwatywnego liberalizmu. W głębszych warstwach snu krytyka systemu jest pretekstem do wywołania pamięci społecznych niesprawiedliwości. Wątki degradacji środowiska na biednej prowincji, wyniszczenia rdzennych Amerykanów, eksperymentowania na ludziach, militarnego interwencjonizmu, a także historia wykluczeń fundują kolaż odzwierciedlający rozbicie amerykańskiej tożsamości. Paradoksem realizowanej krytyki ideologicznej jest proponowane remedium. Podobnie jak we współczesnych Stanach Zjednoczonych, „lekarstwem na społeczną katastrofę neoliberalizmu staje się silniejszy szczep neoliberalizmu" (Tarnoff, 2016), manifestujący się w jednostkowej pracowitości i wysokich aspiracjach. Max budzi się przecież ze snu dzięki sile własnej psychiki - dopiero w momencie, gdy odzyskuje wolę walki i poddaje się mocom optymizmu.

\section{Zmierzch w potudnie}

W czasie gdy Ronald Reagan zapowiadał nadejście „poranka w Ameryce”, Paul Crutzen i John Birks pracowali nad złowróżbnym tekstem Atmosfera po wojnie nuklearnej. Zmierzch w południe. Nastrój końca powodowany był przekonaniem o tym, że misja cywilizacyjna Stanów Zjednoczonych 
wyczerpała się, a schyłek wieku zamiast czasu szczęśliwości przyniesie jedynie kryzys. W snutych proroctwach obawa przed nadchodzącymi kataklizmami zyskiwała zwykle kształt symboli, metafor i alegorii powiązanych z wydarzeniami historycznymi. Kilka lat później ta intuicja okazała się słuszna: wydarzenia z 11 września uzmysłowiły, że Stany Zjednoczone nie posiadły przywileju nietykalności, a inwazyjna polityka zagraniczna ma bezpośrednie i dotkliwe konsekwencje. Zanim jednak rozpoczął się etap „wojny z terroryzmem”, pesymistów roztaczających wizje ponurej przyszłości krytykowano za demoralizujące przywoływanie dawnych win.

Przyjmując założenie, że praca nad lekiem dla dzieci jest elementem „realnej rzeczywistości” i to porażka na tym gruncie powoduje pękniecie integralności umysłu Maksa, zauważymy, że wszystkie epizody inicjowane przez „współosadzonych” w szpitalu psychiatrycznym (a więc przez samego Maksa) odwołują się, w mniejszym lub większym stopniu, do traumy powodowanej moralną klęską amerykańskiego snu. Strukturę narracyjną w uproszczony sposób mogłaby ilustrować poniższa tabela.

\begin{tabular}{|c|c|}
\hline $\begin{array}{l}\text { Pierwszy poziom } \\
\text { Fizyczna rekonwale- } \\
\text { scencja }\end{array}$ & $\begin{array}{l}\text { Max zapada w śpiączkę wskutek wypadku drogowego. Gra kończy się } \\
\text { wybudzeniem bohatera. }\end{array}$ \\
\hline $\begin{array}{l}\text { Drugi poziom } \\
\text { Rehabilitacja zaburzeń } \\
\text { amnestycznych }\end{array}$ & $\begin{array}{l}\text { Pogrążony w śpiączce Max rekonstruuje swój życiorys. Uwzględnia } \\
\text { kluczowe momenty życia: dzieciństwo, śmierć siostry, karierę nauko- } \\
\text { wą, pracę nad wynalezieniem leku, realia branży medycznej, konflikt } \\
\text { z przełożonym - Jacobem Morganem. }\end{array}$ \\
\hline $\begin{array}{l}\text { Trzeci poziom } \\
\text { Szpital psychiatryczny }\end{array}$ & $\begin{array}{l}\text { Pogrążony w śpiączce Max zanurza się w fantasmagorii szpitala psy- } \\
\text { chiatrycznego. Bohater konfrontuje się z niepokojami codzienności } \\
\text { (znanymi z poziomu drugiego), ale w surrealnym świecie przybierają } \\
\text { one wynaturzony, spotworniały kształt. Max okazuje się jednym } \\
\text { z wielu pacjentów osadzonych w „wieży szaleńców”. Manifestacją } \\
\text { zmagań z ogarniającą go paranoją jest konfrontacja z Jacobem Mor- } \\
\text { ganem - groteskowo złowieszczym, szalonym naukowcem. }\end{array}$ \\
\hline $\begin{array}{l}\text { Czwarty poziom } \\
\text { Szpital psychiatrycz- } \\
\text { ny - światy szaleńców }\end{array}$ & $\begin{array}{l}\text { Rzeczywiste zmagania z państwem neoliberalnym nakierowują boha- } \\
\text { tera na eksplorowanie fikcyjnych światów, nadających kształt narracji } \\
\text { o ciemnych kartach amerykańskiej historii. Wszystkie przygody biorą } \\
\text { swój początek w wypaczeniach systemu i społecznych traumach. } \\
\text { W fantasmagorii szpitala psychiatrycznego Max kreuje postaci } \\
\text { swoich współwięźniów. Pacjenci opowiadają więc różne fragmenty tej } \\
\text { samej historii o życiu w późnokapitalistycznym społeczeństwie. } \\
\text { Zanurzanie się w kolejnych czasoprzestrzeniach (wioska przy poletku } \\
\text { dyniowym, Cyrk Gtupców, Wielki Ul, wioska Azteków) pozwala Makso- } \\
\text { wi na rekonstrukcję życiorysu na poziomie drugim. }\end{array}$ \\
\hline
\end{tabular}


Wyobrażona podróż Maksa rozpoczyna się w zakładzie psychiatrycznym postawionym na fundamentach dominacji i kontroli oraz oswajania i dyscyplinowania. Lecznica, podobnie jak świat relacji biznesowych, wymaga od bohatera wyzbycia się podmiotowości (i przemiany w bezwolny obiekt, jak pisał Michel Foucault, omawiając relację pacjent - psychiatra; Foucault, 1987, s. 457). Na poziomie szpitalnym protagonista nie stanowi punktu centralnego fabuły. W omawianej czasoprzestrzeni wszyscy osadzeni są skazami na amerykańskiej tożsamości. W realiach uzdrowiska koncentruje się pięć głównych wyrzutów sumienia, spośród których każdy jest udziałem jednego pacjenta (bohatera fantazji Maksa). Martin przywołuje wojnę cywilizacji, Don klątwę rdzennych Amerykanów, Lenny - odwet natury, balansujący na krawędzi konferansjer - tragedię trupy cyrkowej, a wariant Maksa $\mathrm{z}$ fantasmagorii o szalonym naukowcu - niepohamowaną technofilię doby późnego kapitalizmu.

Opowieści szaleńców wynikają z lęków amerykańskiej teraźniejszości, ale mają przede wszystkim istotne zakotwiczenie w przeszłości. Starcie między centaurami i insektoidami rezonuje wojną w Zatoce Perskiej, jednak wywołuje też pamięć konfliktu wietnamskiego. Epizod aztecki może sugerować wątki politycznej i ekonomicznej kolonizacji biednych peryferii, ale nawiązuje głównie do holocaustu rdzennej ludności oraz grabieży dóbr w Ameryce Północnej. Zemsta natury kojarząca się z niebezpieczeństwem epidemii (między innymi wirusa Ebola w latach 90.) odradza pamięć nieetycznych eksperymentów na ludziach. Niechęć wobec dyskursu równościowego odżywa w grze pod postaciami zdeformowanych cyrkowców - niegdysiejszych „dziwolągów” wystawianych na widok publiczny w pokazach kuriozów. Wreszcie strach przed „rozwojem” jest zilustrowany działalnością szalonego naukowca podejmującego się testów biotechnologicznych i sięgającego do metod eugeniki. Maks, jako uosobienie moralnego wyrzutu sumienia Ameryki, na moment przyznaje głos wykluczonym.

Zawołanie Clintona o ,jednej Ameryce w XXI wieku”, wbrew intencjom prezydenta, przypomniało o istnieniu wielu małych ojczyzn, z perspektywy elit często zapomnianych: Ameryk ludobójstwa i opresji rdzennej ludności, prześladowań klasowych i rasowych, eksperymentów medycznych i poligonów doświadczalnych, małych miasteczek - 
eksploatowanych i wyzyskiwanych w imię interesów najbogatszych. Ostatecznie jednak w grze subwersywny potencjał tej narracji zostaje stłamszony. Tragedia rozchwianej tożsamości jest bowiem sprowadzona do jednostkowych przejawów szaleństwa i histerii, które można powściągnąć i utrzymać w ryzach. Jak zauważył Philip Lamy, nastroje paranoiczne często służyły kultywowaniu indywidualizmu, ponieważ sympatycy ideologii sukcesu zakładali, że przyszłe realia nie będą oparte na kooperacji i solidarności, lecz na prawie silniejszego (Lamy, 1996, s. 262). W podobny sposób w Sanitarium dokonuje się pochwały neoliberalizmu. Max przepracowuje rozproszone traumy i odnajduje w sobie mit ,jednej Ameryki” - ostatecznie sprawdza się jako mąż, ojciec, brat i członek społeczeństwa, ale przede wszystkim jako indywidualista i piewca amerykańskiej wyjątkowości.

\section{Jednej Ameryki nigdy nie było}

Sanitarium przypomina o istnieniu świata sprzeczności, w którym amerykańskie marzenie - optymizm ekonomiczny i poczucie moralnej wyższości - zderza się z koszmarem codzienności. W dialektyce ufundowanej na tradycji amerykańskiego gotyku ${ }^{5}$ ujawnia się mechanizm uwewnętrzniania lęków (Fisher, 1981, s. 177). Na przełomie tysiącleci narodowy eksperyment Amerykanów powołał do istnienia schizofreniczną tożsamość, która nierzadko prowadziła do krain mrocznych imaginacji. Z obaw teraźniejszości rodziła się destrukcyjna tęsknota za możliwym lub utraconym szczęściem, a zwłaszcza: starymi, dobrymi czasami. W Sanitarium epizod rozgrywający się na poletku dyń uzmysławia jednak deficyty w wizji bukolicznych Stanów Zjednoczonych.

${ }^{5}$ Kategoria amerykańskiego gotyku (American Gothic) powstała na przełomie XVIII i XIX stulecia w Stanach Zjednoczonych. W powieściach autorów, których wyobraźnia została naznaczona etyką purytańską, często uobecniał się koszmar stanowiący rewers amerykańskiego snu. Zdaniem Erica Savoya myśl spajająca teksty kultury z tego nurtu jest bardziej skomplikowana: amerykańska ideologia (charakteryzująca się oświeceniowym optymizmem i uprzywilejowaniem wartości takich jak wolność czy jednostkowe szczęście) oraz historia Stanów Zjednoczonych mają swoje mroczne i krwawe oblicze. Nawiedza ono teraźniejszość - rozbija psychiczny komfort, pozostawia poczucie winy, rodzi obawę przed wybuchem przemocy (Savoy, 2002, s. 167). 
Przejście przez ziemię uprawną, w wielu kręgach kulturowych uznawane za symbol powodzenia (wyrażający łączność z przeszłością, naturą, innymi ludźmi - a więc wartościami stojącymi także u podstaw romantycznych wyobrażeń małomiasteczkowej Ameryki; Ott, 2012, s. 174), kończy się odkryciem zmutowanej rośliny - obmierzłej istoty transformującej i pochłaniającej dziecięce ciała. Blask komety, obserwowany przez społeczność Genet, przypomina o cierpieniu obywateli Stanów Zjednoczonych, którzy tuż po obejrzeniu tajemniczych rozbłysków odczuwali deformację i rozpad swoich ciał. Być może sielankowa Ameryka nigdy nie istniała, skoro kraj został ufundowany na nieszczęściu swoich mieszkańców.

Jeśli założyć, że szpital psychiatryczny jest miejscem eskalacji szaleństwa i kreacji groteskowych realiów, to wydźwięk Sanitarium okazuje się regresywny. Opuszczenie uzdrowiska jest możliwe jedynie w przypadku uznania ułudnych przymiotów amerykańskiej tożsamości - tej, która odznacza się walecznością, jest nieskażona defetyzmem i pokłada wiarę w znaczenie jednostkowego wysiłku. Od kuracjusza wymaga się zaakceptowania grzechów przeszłości. Niechęć wobec rozpamiętywania win jest oczywistym nawiązaniem do (rzekomo) niepatriotycznej, niezadowolonej części społeczeństwa, której orientację jeden z liberalnych dziennikarzy w latach 90. dookreślał mianem „kultury ciągłego sprzeciwu” (Zinn, 2010, rozdział 22). Choć zwykle chodziło nie o antypaństwową retorykę, a o rozczarowanie prezydenturą Clintona, to wspominanie traum (oraz infekowanie zbiorowej pamięci Amerykanów pesymizmem) nabierało u schyłku tysiąclecia tonacji niemal wichrzycielskiej. Jak zwracał uwagę Arthur Neal, każde tożsamościowe pęknięcie domagało się przeprowadzenia natychmiastowych działań naprawczych, służących zażegnaniu nieprzyjemnych odczuć (Neal, 2005, s. 3-4).

W momencie przełomu malkontenci zostali przeniesieni do symbolicznego azylu, w którym egzorcyzmowano ich zmartwienia i odnawiano wiarę w siłę Ameryki. W ostatecznym rozrachunku system nie mógł okazać się zły czy zawodny. Zagrożenie stanowił raczej człowiek, który utracił wolę działania. $Z$ tego względu u schyłku podróży Maksa wyobrażony Morgan nie przypomina już korporacyjnego decydenta. Antagonista zmienia kształty i jako sobowtór głównego bohatera objaśnia mu zasady funkcjonowania rzeczywistości. Stosując sztuczki trickstera, zwierzchnik 
korporacji przekonuje swoje dobre, choć nieco zagubione odbicie: „Brakuje ci siły i odwagi [...]. Jesteś swoim największym wrogiem”. Szalony naukowiec staje się wtedy sojusznikiem Maksa, który uwalnia protagonistę z psychicznej matni. Właśnie w tym momencie zawiązuje się wspomniany wcześniej sojusz. Poprzez kult indywidualizmu i pozorną troskę rozgrzesza się firmę medyczną i jej nieetyczne praktyki oraz zapomina o wyrządzonych przez nią krzywdach. W zamykającej grę sekwencji obaj mężczyźni deklarują: „To koniec”, jakby byli dwiema stronami jednego bytu. Symboliczne zespolenie Maksa i Morgana wyraża amerykańską rację stanu: kapitalizm okazuje się agregatem najwyżej cenionych wartości, a konserwatyzm zapewnia mu moralną legitymizację.

Bohater Sanitarium budzi się ze śpiączki, ponieważ taki jest wymóg doktryny sukcesu. Max „wyzdrowiał” - po opuszczeniu koszmaru zaczyna na dobre śnić swój amerykański sen. Podejrzanie optymistyczne zakończenie (sukces i sława, zjednoczenie z żoną, narodziny dziecka) może sugerować rysę ideologiczną, którą wprost obnaża fabuła Stasis. W stworzonym przez The Brotherhood Games tytule z 2015 roku akt oskarżenia jest bezceremonialny: władze korporacji Cayne ponoszą winę za masowy mord. W Sanitarium krytyka pozostaje niemal niewidoczna.

W trakcie wędrówki po groteskowych wnętrzach szpitala psychiatrycznego Max spotyka martwą kobietę, która ostrzega go: „«Ktoś» zrobi wszystko, byle tylko nie wypuścić cię z domu wariatów [...]. Twoje odejście ze szpitala równa się upadkowi «tego kogoś»”. Denatka celowo nie dookreśla „tej osoby”. To moment, w którym pojawia się przeczucie, że szaleństwo jest elementem amerykańskiej tożsamości. Moment opuszczenia lecznicy nie musi równać się wyzdrowieniu - może być początkiem właściwego stadium choroby. Historia Stanów Zjednoczonych, wypływająca z obłąkanej przemocy - podboju, śmierci i zniszczenia, domagająca się przepisywania historii i zapominania ofiar, nade wszystko uprzywilejowuje schizofreniczność. Wydaje się, że pacjent z 12 małp rozumiał, że w świecie totalnej paranoi to „równowaga umysłowa” stanowi objaw choroby. W tym wariancie ozdrowienie byłoby bliskie moralnemu upadkowi bohatera Sanitarium. Wiara w koniec złego snu i przyzwolenie na wybiórczą amnezję oznaczają przecież pogodzenie się z patologiami późnego kapitalizmu - tymi, które na co dzień sprowadzają zagładę na świat Maksa. 


\section{Literatura}

Buckland, W. (2009). Introduction. Puzzle plots. W: W. Buckland (red.), Puzzle films. Complex storytelling in contemporary cinema (s.1-12). Malden: Wiley-Blackwell.

Fisher IV, B. F. (1981). The residual Gothic impulse: 1824-1873. W: M. B. Tymn (red.), Horror Literature. A Core Collection and Reference Guide (s. 176-189). New York: R. R. Bowker Company.

Foucault, M. (1987). Historia szaleństwa $w$ dobie klasycyzmu (tłum. H. Kęszycka). Warszawa: Państwowy Instytut Wydawniczy.

Furedi, F. (2006). Culture of fear revisited. Risk-taking and the morality of low expectation. New York: Continuum International Publishing Group.

Glassner, B. (2000). The culture of fear. Why Americans are afraid of the wrong things. New York: Basic Books.

Hodgson, G. (2009). The myth of American exceptionalism. New Haven: Yale University Press.

Hofstadter, R. (1996). The paranoid style in American politics and other essays. Cambridge: Harvard University Press.

Huyssen, A. (2010). Twilight memories. Marking time in a culture of amnesia. New York: Routledge.

Kilgore, C. M. (2007). Medium of gameplay. Ames: praca magisterska. Online: <https://dr.lib.iastate.edu/entities/publication/5b428dd67ccd-4bc2-841e-db7804adeda2>. Data dostępu: 28 grudnia 2019.

Kornberger, S. (2014). Vampire, Monster, irre Wissenschaftler. So viel Europa steckt in Hollywoods goldener Horrorfilmära. Hamburg: Diplomica Verlag.

Lamy, P. (1996). Millennium rage. Survivalists, white supremacists, and the doomsday prophecy. New York: Plenum Press.

Marak, K. (2021). "If the dog dies, I quit": Blair Witch and the problems of contemporary psychological horror games. Studia Humanistyczne AGH, 20(2), 57-70.

Neal, A. G. (2005). National trauma and collective memory. London: Routledge.

Ott, C. (2012). Pumpkin. The curious history of an American icon. Seattle: University of Washington Press.

Pasetto, C (4 grudnia 1998). Postmortem. DreamForge's Sanitarium. Online: <https://www.gamasutra.com/view/feature/3299/postmortem_dreamforges_sanitarium.php>. Data dostępu: 28 grudnia 2019. 
Rautzenberg, M. (2015). Navigating uncertainty. Ludic epistemology in an age of new essentialisms. W: M. Fuchs (red.), Diversity of play (s. 83-106). Lüneburg: Meson Press.

Savoy, E. (2002). The rise of American Gothic. W: J. E. Hogle (red.), The Cambridge companion to Gothic fiction (s.167-188). New York: Cambridge University Press.

Steger, M. B. (2009). Globalisms. The great ideological struggle of the twenty-first century. Lanham: Rowman \& Littlefield Publishers.

Stohl, A. (2000). Der Narrenturm oder die dunkle Seite der Wissenschaft. Wien: Böhlau Verlag.

Tarnoff, B. (13 grudnia 2016). Neoliberalism turned our world into a business. And there are two big winners. Online: <https://www.theguardian.com/us-news/2016/dec/13/donald-trump-silicon-valley-leadersneoliberalism-administration>. Data dostępu: 28 grudnia 2019.

Troy, G. (2013). Morning in America. How Ronald Reagan invented the 1980's. Princeton: Princeton University Press.

Valentine, K. D., Jensen, L.J. (2016). Examining the evolution of gaming and its impact on social, cultural, and political perspectives. Hershey: Information Science Reference.

Wheen, F. (2012). How mumbo-jumbo conquered the world. A short history of modern delusions. London: Harper Perennial.

Wiseman, G. (2001). Concepts of non-provocative defence. Ideas and practices in international security. London: Palgrave Macmillan.

Zinn, H. (2010). A people's history of the United States, 1492-present. New York: Harper Perennial Modern Classics. Ebook.

\section{Filmografia}

12 małp (1995). Reż. T. Gilliam. USA.

Amerykański horror (1995-1996). USA.

Drabina Jakubowa (1990). Reż. A. Lyne. USA.

Gabinet doktora Caligari (1920). Reż. R. Wiene. Niemcy.

Millennium (1996-1999). USA.

Sucker Punch (2011). Reż. Z. Snyder. USA, Kanada.

Wyspa tajemnic (2010). Reż. M. Scorsese. USA.

Z Archiwum X (1993-2002). USA. 


\section{Ludografia}

Black Isle Studios (1999). Planescape: Torment [PC]. Interplay Entertainment, USA.

Cyberdreams (1992). Dark Seed [PC]. Cyberdreams, USA.

Cyberdreams (1995). Dark Seed II [PC]. Cyberdreams, USA.

DigiFX Interactive (1996). Harvester [PC]. Merit Studios, USA.

DreamForge Intertainment (1995). Chronomaster [PC]. IntraCorp, USA.

DreamForge Intertainment (1998). Sanitarium [PC]. ASC Games, USA.

Team Silent (1999). Silent Hill [Playstation]. Konami, Japonia.

The Brotherhood Games (2015). Stasis [PC]. The Brotherhood Games, South Africa.

The Dreamer's Guild (1995). I Have No Mouth, and I Must Scream [PC]. Cyberdreams, USA.

dr Wojciech Sitek - kulturoznawca, filmoznawca. Zajmuje się ideologicznym podłożem kina amerykańskiego i społecznym fenomenem wideokaset, wojciech.

\section{Niepokoje końca wieku. Sanitarium i rekonwalescencja amerykańskiej tożsamości}

Abstrakt: W amerykańskiej kulturze popularnej lat 90. wykształcił się nurt pesymistycznych narracji realizowanych w estetyce sennego koszmaru. Twórcy gier typu Sanitarium przywoływali pamięć historycznych porażek, ale też przestrzegali przed nadciągającą zagładą. W niniejszym artykule gra studia DreamForge Intertainment jest analizowana jako reprezentacja rozpadu amerykańskiej tożsamości. Zjednej strony porusza się w niej temat społecznego kryzysu, który dotknął Stany Zjednoczone u schyłku tysiąclecia. Z drugiej strony w fabule Sanitarium wybrzmiewa wiara w możliwość odnowienia moralnej sity Ameryki.

Słowa kluczowe: kultura Stanów Zjednoczonych, lęki nowego tysiąclecia, gry wideo, Sanitarium 